\title{
Risk factors associated with physical and mental distress in people who report a COPD diagnosis: latent class analysis of 2016 behavioral risk factor surveillance system data
}

This article was published in the following Dove Medical Press journal:

International Journal of COPD

\author{
Michael Stellefson' \\ Samantha R Paige ${ }^{2}$ \\ Adam E Barry 3 \\ Min Qi Wang ${ }^{4}$ \\ Avery Apperson'
}

'Department of Health Education \& Promotion, East Carolina University,

Greenville, NC, USA; ${ }^{2}$ STEM

Translational Communication

Center, University of Florida, Gainesville, FL, USA; ${ }^{3}$ Department of Health and Kinesiology, Texas A\&M University, College Station, TX USA; ${ }^{4}$ Department of Behavioral and Community Health, University of Maryland, College Park, MD, USA
Correspondence: Michael Stellefson East Carolina University, Department of Health Education and Promotion, 3202 Carol G. Belk Building, Greenville, NC 27858, USA

Tel +I 2523282105

Email stellefsonm17@ecu.edu
Introduction: Challenges associated with COPD increase patients' risk of physical immobility and emotional distress, perpetuating a cycle of symptomatic living that hinders patients' selfmanagement and adherence to a treatment regimen. There is limited evidence available on how discrete behavioral and health risk factors contribute to the physical and mental distress experienced by people living with COPD.

Purpose: This secondary data analysis of 2016 Behavioral Risk Factor Surveillance System (BRFSS) sought to identify subgroups of people with COPD who were at the highest risk for physical and mental distress.

Methods: We selected 16 relevant risk indicators in four health-related domains -1 ) health risk behaviors, 2) lack of preventive vaccinations, 3) limited health care access, and 4) comorbidities - as predictors of physical and mental health-related quality of life (HRQoL) in the COPD population. Latent class modeling (LCM) was applied to understand how various health-related indicators in these four health domains influenced reports of physical and/or mental distress.

Results: The majority of BRFSS respondents who reported a COPD diagnosis experienced physical (53.76\%) and/or mental (58.23\%) distress in the past 14 days. Frequent physical and mental distress were more common in females with COPD in the 45-64 years age group, who were also identified as white and in the lower socioeconomic group. Respondents with intermediate- to high-risk behaviors, intermediate to multiple comorbidities, limited access to health care, and intermediate to low use of preventive vaccinations were more likely to report frequent physical distress compared to the low-risk respondents. Similarly, respondents with high-risk behaviors, intermediate to multiple comorbidities, and low use of preventive vaccinations were more likely to report frequent mental distress than the low-risk group.

Discussion: This analysis of updated 2016 BRFSS data identified high-risk Americans with COPD who could benefit from disease management and secondary/tertiary health promotion interventions that may improve HRQoL. Future research should address noted disparities in risk factors, particularly among low socioeconomic populations living with COPD.

Keywords: COPD, HRQoL, physical distress, mental distress, latent class modeling, BRFSS

\section{Introduction}

COPD, a leading cause of chronic disease-attributed death, is a complex, multi-faceted, and progressive condition that detrimentally affects the structural and physiological functioning of the respiratory system. Patients with COPD experience varying degrees of dyspnea and mucus/sputum production that exacerbate inefficient breathing. 
These challenges increase patients' risk of physical immobility and emotional distress, ${ }^{1-4}$ perpetuating a vicious cycle of symptomatic living that hinders patients' self-management and adherence to a treatment regimen. In the United States in 2010, medical costs attributable to COPD were $\sim \$ 72.7$ billion and are forecasted to an estimated $53 \%$ rise by $2020 .^{5}$ The efforts to understand the modifiable behavioral and environmental factors that contribute to patients' physical and emotional distress represent the fundamental public health goals to alleviate the burden of COPD worldwide, advance the health and well-being of this underserved patient population, and ultimately improve quality of life..$^{6,7}$

COPD is a progressive condition, meaning that breathing challenges and associated physical symptoms worsen over time. Timely and proactive management is necessary to alleviate the burden of behavioral and health-related factors that expedite the disease progression. Despite evidence that if a patient quits smoking, the patient can slow down the decline of lung functioning and can improve their chance of surviving COPD,${ }^{8}$ nearly $40 \%$ of patients with COPD continue to smoke after a COPD diagnosis. ${ }^{9}$ Similarly, it is a national priority to promote flu vaccine uptake against respiratory viruses among patients with COPD; ${ }^{10}$ however, over half $(51.5 \%)$ of patients with COPD in the United States report never receiving an influenza vaccination. ${ }^{11}$ Given their poor disease management practices, patients with COPD who smoke or have contracted the influenza virus experience negative health-related outcomes that compromise their quality of living. ${ }^{12,13}$ Observational studies identify smoking status and contracting influenza as predictors of one another, ${ }^{11}$ making it difficult to assess their temporal relationship and unique contribution to emotional and physical distress. There is limited evidence that examines how sociocultural behavioral and health risk factors, including smoking behaviors and vaccine avoidance, contribute to the physical and mental distress experienced by people with COPD in the United States.

The Behavioral Risk Factor Surveillance System (BRFSS $)^{14}$ hosts a population-based survey that empirically monitors numerous domains associated with health-related quality of life (HRQoL), including health risk behaviors, vaccination rates, access to health care, and comorbid health conditions. Several indicators are used in the BRFSS to describe each of the domains, many of which are highly correlated and interdependent. Conventional analytical methods traditionally used to analyze the effects of these domains generally focus only on individual risks, making them less than ideal for untangling complex relationships among various health-related indicators. Latent class modeling (LCM) represents an efficient analytical strategy for summarizing indicators of physical and mental distress using latent classes that define risk classes of individuals. ${ }^{15}$ Separating respondents into distinct risk categories affords researchers the opportunity to use regression-based analyses to determine associations between latent classes and unique dimensions of HRQoL, including mental and physical distress. Accordingly, this study applied LCM procedures described elsewhere ${ }^{15}$ to 1) summarize and group health indicators of people with COPD into mutually exclusive health domains and 2) identify subgroups of people with COPD who are at the highest risk for physical and mental distress.

\section{Method \\ Data source}

The BRFSS, administered by the Centers for Disease Control and Prevention in all 50 states and 4 US territories, is a population-based, random-digit-dialed telephone survey that monitors access to health care, certain health conditions, and behavioral health risks that contribute to the leading causes of disease and death among adults aged $\geq 18$ years. The BRFSS methods, including sample selection and weighting procedures, are described elsewhere. ${ }^{16}$ All BRFSS questionnaires, data, and reports are available at http://www.cdc.gov/brfss/.

This investigation explored the 2016 BRFSS dataset. In particular, this study constituted all respondents who answered "Yes" to the question "Has a doctor, nurse, or other health professional EVER told that you have chronic obstructive pulmonary disease (COPD), emphysema or chronic bronchitis?" $(\mathrm{N}=32,791)$. We selected 16 relevant risk indicators in four health-related domains - health risk behaviors, lack of preventive vaccinations, limited health care access, and comorbidities - that are known to independently influence physical and mental HRQoL outcomes in people living with COPD ${ }^{12,17-19}$ (Figure 1).

\section{Indicators}

We assessed five health risk behaviors among respondents who reported being diagnosed with COPD: 1) current tobacco smoking (smokes cigarettes every day or some days); 2 ) binge drinking ( $\geq 5$ drinks on at least one occasion in the past 30 days for men, $\geq 4$ drinks on at least one occasion over the past 30 days for women); 3 ) higher risk drinking ( $\geq 3$ drinks on at least one occasion over the past 30 days for men, $\geq 2$ drinks on at least one occasion over the past 30 days for women); 4) e-cigarette use (smoked e-cigarettes every day or some days); and 5) use of chewing tobacco (current use of chewing 


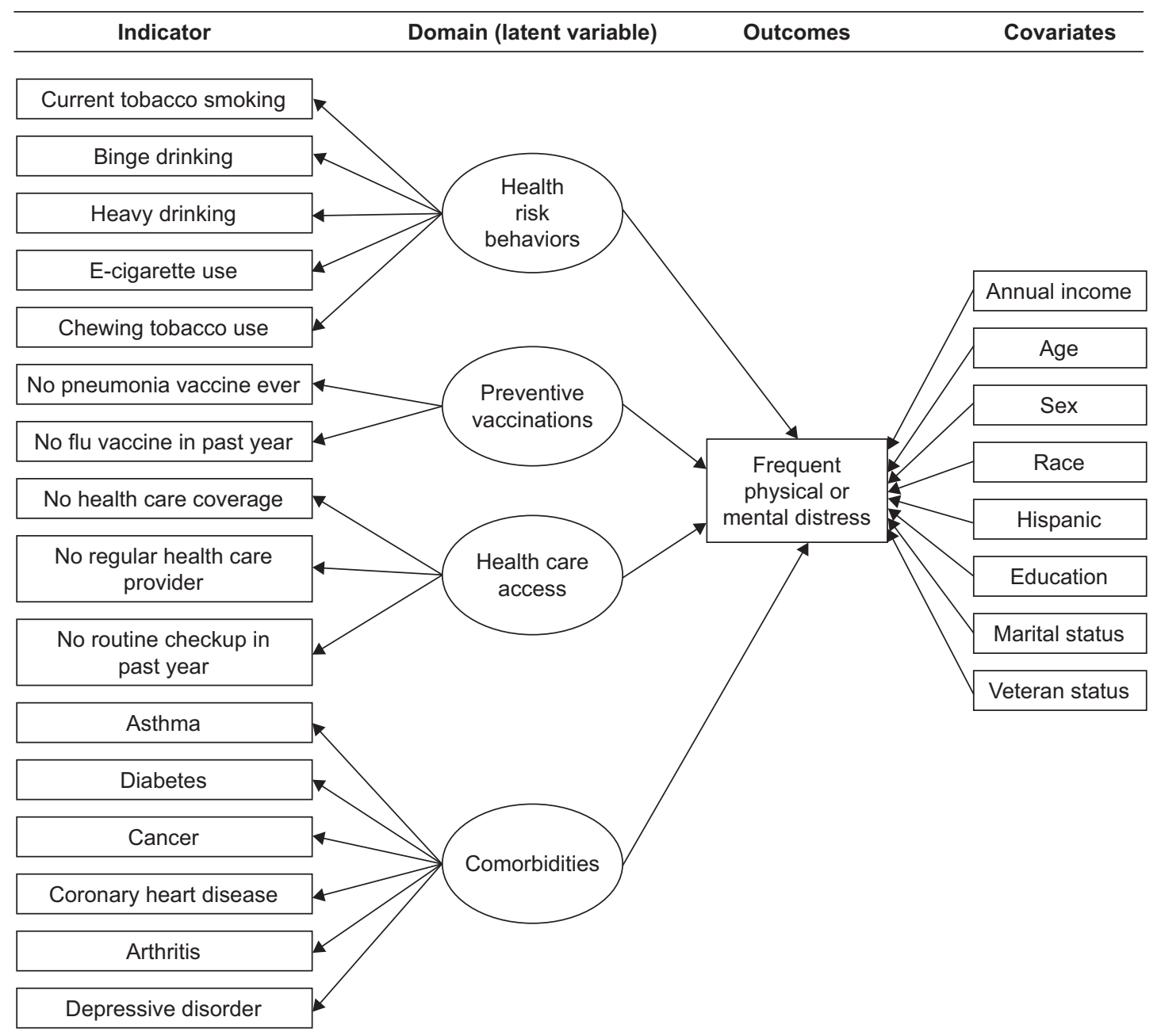

Figure I Sixteen indicators, four health domains, two HRQoL outcomes, and eight covariates for LCM approach to analyze 2016 data collected from individuals with COPD who responded to the BRFSS survey $(\mathrm{N}=32,791)$. Data in this figure is adapted based on the indicators, domains and covariates tested by jiang and Zack. ${ }^{15}$

Abbreviations: HRQoL, health-related quality of life; LCM, latent class modeling; BRFSS, Behavioral Risk Factor Surveillance System.

tobacco, snuff, or snus every day or some days). We assessed lack of preventive vaccinations obtained by BRFSS respondents with COPD using two items: 1) never had a pneumonia vaccination and 2) had no influenza vaccination in the past 12 months. Three questions were asked to determine limited health care access: 1 ) being uninsured (no health care coverage); 2) having no regular health care provider; and 3) having no routine checkup in the past year. We also identified if respondents reported ever being told by a health professional if they had any of the following comorbidities: asthma, diabetes, coronary heart disease, cancer, rheumatoid arthritis, gout, lupus, fibromyalgia, or depressive disorders (ie, depression, major depression, dysthymia, or minor depression).

\section{Outcomes: physical and mental HRQoL}

HRQoL is best assessed with reference to a quantified period of time. Therefore, poor HRQoL was assessed for both physical health ("Now thinking about your physical health, which includes physical illness and injury, for how many days during the past 30 days was your physical health not good?") and mental health ("Now thinking about your mental health, which includes stress, depression, and problems with emotions, for how many days during the past 30 days was your mental health not good?"). Quantifying these estimates in terms of days in the most recent month avoids the need to use more complex weights in aggregating and comparing data based on multiple choice questions. ${ }^{10}$ Two dependent variables were dichotomized in the following manner: 14 or more days (more frequent physical or mental distress) and 0-13 days (less frequent physical or mental distress). People who experience symptoms of physical and mental distress for at least 2 weeks (14 days) over the course of a month tend to function at lower levels. ${ }^{20-22}$ Several prior studies have coded these BRFSS items in an 
analogous manner to identify distress impacting mental and physical HRQoL. ${ }^{15,23,24}$

\section{Covariates}

Potential confounders in multivariable analyses included age group (18-44 years, 45-64 years, $\geq 65$ years), sex (male, female, refused), race (White, Black or African American, American Indian or Alaska Native, Asian, Pacific Islander, other race, no preferred race), ethnicity (Hispanic, not Hispanic), education level (never attended school or only attended kindergarten, grades 1 through 8, grades 9 through 11, grade 12 or General Education Development (GED), college 1-3 years, college 4 years or more), annual income $(<\$ 20 \mathrm{~K}, \$ 20 \mathrm{~K}-\$ 34,999, \$ 35 \mathrm{~K}-\$ 49,999$, $\$ 50 \mathrm{~K}-$ $\$ 74,999$, $\geq \$ 75,000$ ), marital status (married, divorced, widowed, separated, never married, member of an unmarried couple), and veteran status (served on active duty in US military, did not serve on active duty in US military).

\section{Data analysis}

LCM collapses many discrete indicators into a few meaningful latent classes (ie, categories that condense levels of a domain) and estimates the probability that a person belongs to a specific latent class. The response pattern is the unit of analysis. ${ }^{25,26}$ In this study, rather than using summated indices of risk behaviors or health conditions, researchers used LCM, which enabled research to consider numerous correlated items as indicators of four health domains related to the physical and mental HRQoL outcomes. For example, for the 5 indicators of risky health behaviors, LCM can summarize the 32 possible response patterns $\left(2^{5}=32\right)$ into an interpretable number of latent classes.

The latent class model provides the prevalence of each latent class (marginal probabilities) and the class-specific response probabilities of each indicator (conditional probabilities). To determine the most parsimonious model, we sequentially fitted models from class 1 to more latent classes, ${ }^{26,27}$ compared successive models using the Bayesian Information Criterion (BIC), and chose the model with the smallest BIC values. ${ }^{28}$ The smallest BIC values for each health domain corresponded with the most parsimonious model, which was subsequently plotted and graphed. LCM uses a measurement model in which individuals can be classified into mutually exclusive and exhaustive types or latent classes, based on their pattern of answers on a set of variables. For example, if class 1 shows that respondents reported high (eg, 60\% reported smoking, 90\% heavy drinking) on most (not necessarily all) of the risk behaviors compared with other classes, this class is interpreted as the "high risk" group. On the other hand, if class 3 shows that respondents reported low (eg, 20\% reported smoking, 30\% heavy drinking) on most (not necessarily all) of the risk behaviors compared with other classes, this class is interpreted as the "low risk" group.

To examine the influence of higher risk classes on variable domains of health, we performed two sets of logistic regressions to assess the association of each latent class with the two outcomes, physical and mental distress, affecting HRQoL. These models estimate ORs with 95\% CIs for frequent physical and mental distress of the higher risk classes relative to the lower risk classes, adjusting for age, sex, race, ethnicity, education, income, marital status, and veteran status. Merging LCM with logistic regression provides several advantages when analyzing complex datasets such as the BRFSS. ${ }^{15}$ First, grouping of correlated health indicators into health domains allows indicators to be correlated with outcomes through discrete domains, which minimize multicollinearity. Second, combining LCM and logistic regression models allows several indicators to contribute to discrete domains, thus improving domain reliability by reducing variation in health domains caused by a single indicator(s). Finally, once the number of latent classes is selected, LCM does not require specification of arbitrary cutoffs to distinguish classes. ${ }^{15} \mathrm{We}$ conducted all LCM analyses in Mplus (version 7.3) because this software can accommodate the complex sampling design (ie, strata, primary sampling unit, and weight) of BRFSS. ${ }^{15}$ We performed all other analyses with Statistical Analysis System (SAS) version 9.4 Survey procedures. ${ }^{29}$ Significance was set at $P<0.05$.

\section{Results}

The demographics by physical and mental distress are presented in Table $1(\mathrm{~N}=32,791)$. The vast majority of respondents were over the age of 45 years and non-Hispanic Caucasian, and over half were female. Over $20 \%$ of respondents $(n=4,643 ; 23.2 \%)$ did not have a high school degree, while only $12.4 \%(n=6,582)$ reported $\geq 4$ years of college. More than one-third $(n=11,907 ; 36.3 \%)$ reported annual incomes $<\$ 20 \mathrm{~K}$, while $25 \%(\mathrm{n}=7,548)$ reported earning $>\$ 50 \mathrm{~K}$ per year. About $42 \%(\mathrm{n}=12,784)$ of respondents were married, with a sizable proportion $(\sim 40 \%$; $\mathrm{n}=15,586)$ identifying as divorced, widowed, or separated. Over $80 \%(n=26,872 ; 83.5 \%)$ of BRFSS respondents with COPD reported no prior experience in the US military.

The majority of respondents with COPD reported experiencing physical (53.76\%) and/or mental (58.23\%) distress in the past 14 days, indicative of "frequent distress." In adults 
Table I Prevalence of frequent physical and mental distress, by demographic characteristics, COPD population, Behavioral Risk Factor Surveillance System, $2016^{\text {a }}$

\begin{tabular}{|c|c|c|c|}
\hline $\begin{array}{l}\text { Demographic } \\
\text { characteristics }\end{array}$ & $\begin{array}{l}\text { No of respondents } \\
\text { with } \text { COPD }^{\mathrm{a}}, \mathrm{n}=32,\left.79\right|^{\mathrm{b}}(\%)\end{array}$ & $\begin{array}{l}\text { Frequent mental distress, } \\
\%(95 \% \mathrm{Cl})^{\mathrm{b}}, \mathrm{n}=7,734\end{array}$ & $\begin{array}{l}\text { Frequent physical distress, } \\
\%(95 \% \mathrm{Cl})^{\mathrm{b}} \mathrm{n}=12,690\end{array}$ \\
\hline \multicolumn{4}{|l|}{ Age } \\
\hline 18-44 years & $3,199(20.6)$ & $53.4(49.8,57.1)$ & $43.6(39.8,47.4)$ \\
\hline $45-64$ years & $13,124(42.9)$ & $58.9(56.6,61.2)$ & $64.0(61.9,66.0)$ \\
\hline$\geq 65$ years & $16,468(36.5)$ & $43.2(40.2,46.2)$ & $58.5(56.4,60.7)$ \\
\hline \multicolumn{4}{|l|}{ Sex } \\
\hline Male & $12,752(44.2)$ & $54.1(51.2,57.0)$ & $58.2(55.9,60.5)$ \\
\hline Female & $20,039(55.8)$ & $53.5(5 I .4,55.5)$ & $58.1(56.3,60.0)$ \\
\hline \multicolumn{4}{|l|}{ Race } \\
\hline White & $28,043(80.9)$ & $53.4(51.7,55.2)$ & $59.0(57.5,60.5)$ \\
\hline Black or African American & $2,642(13.3)$ & $52.6(46.9,58.3)$ & $52.6(47.2,58.1)$ \\
\hline American Indian or Alaskan Native & $892(2.2)$ & $6 I .4(5 I .8,7 \mid . I)$ & $68.6(6 \mid .4,75.8)$ \\
\hline Asian & $210(1.4)$ & $37.3(15.8,58.8)$ & $37.0(19.7,54.2)$ \\
\hline Native Hawaiian or other Pacific Islander & $161(0.2)$ & $69.7(52.3,87.0)$ & $69.8(55.9,83.6)$ \\
\hline Other race & $391(1.7)$ & $62.1(50.2,74.1)$ & $55.9(44.6,67.3)$ \\
\hline No preferred race & $102(0.3)$ & $57.0(38.3,75.7)$ & $69.7(54.1,85.3)$ \\
\hline \multicolumn{4}{|l|}{ Hispanic } \\
\hline Yes & $\mathrm{I}, 484(8.8)$ & $57.9(51.6,64.2)$ & $57.0(51.1,62.8)$ \\
\hline No & 31,307 (9I.2) & $53.3(51.5,55.0)$ & $58.3(56.8,59.8)$ \\
\hline \multicolumn{4}{|l|}{ Education } \\
\hline Less than a high school degree & $4,643(23.2)$ & $62.4(58.7,66.2)$ & $66.7(63.6,69.8)$ \\
\hline Grade 12 or GED & II,583 (33.0) & $54.3(51.5,57.2)$ & $57.9(55.4,60.3)$ \\
\hline College I-3 years & $9,983(31.4)$ & $50.7(47.7,53.7)$ & $56.2(53.6,58.8)$ \\
\hline College $\geq 4$ years & $6,582(12.4)$ & $40.0(36.5,43.5)$ & $45.3(42.3,48.2)$ \\
\hline \multicolumn{4}{|l|}{ Annual income } \\
\hline$<\$ 20,000$ & II,907 (36.3) & $64.1(61.6,66.5)$ & $68.1(65.9,70.2)$ \\
\hline$\$ 20,000-\$ 34,999$ & $8,879(25.4)$ & $51.7(48.4,55.0)$ & $57.1(54.5,59.8)$ \\
\hline$\$ 35,000-\$ 49,999$ & $4,457(13.1)$ & $46.8(41.8,51.9)$ & $48.1(43.8,52.5)$ \\
\hline$\$ 50,000-\$ 74,999$ & $3,568(11.0)$ & $40.5(34.7,46.4)$ & $49.0(44.1,53.9)$ \\
\hline$\geq \$ 75,000$ & $3,980(14.2)$ & $37.2(32.3,42.1)$ & $44.0(39.5,48.5)$ \\
\hline \multicolumn{4}{|l|}{ Marital status } \\
\hline Married & I2,784 (42.2) & $47.8(44.9,50.6)$ & $55.9(53.5,58.2)$ \\
\hline Divorced & $7,58 \mid(20.5)$ & $60.3(57.2,63.4)$ & $65.4(62.6,68.2)$ \\
\hline Widowed & $6,857(14.5)$ & $52.7(49.0,56.4)$ & $61.4(58.3,64.6)$ \\
\hline Separated & $\mathrm{I}, \mathrm{I} 48(4 . \mathrm{I})$ & $62.2(55.0,69.3)$ & $67.7(61.9,73.5)$ \\
\hline Never married & $3,522(14.6)$ & $55.7(51.5,59.9)$ & $48.7(44.6,52.8)$ \\
\hline Member of an unmarried couple & $797(4.1)$ & $54.1(43.8,64.4)$ & $54.4(43.8,65.1)$ \\
\hline \multicolumn{4}{|l|}{ Veteran status } \\
\hline Yes & $5,919(16.5)$ & $54.2(49.8,58.7)$ & $59.7(56.3,63.1)$ \\
\hline No & $26,872(83.5)$ & $53.6(5 \mid .8,55.5)$ & $57.9(56.3,59.5)$ \\
\hline
\end{tabular}

Notes: "BRFSS respondent inclusion criteria was answer of "Yes" for the question if ever told of COPD, emphysema, or chronic bronchitis diagnosis by health care provider. bPercentages reflect proportion of respondents experiencing distress within each demographic category subgroup. Some categories do not add to the total because of missing responses.

with COPD within the 45- to 64-year-old age group who also indicated that they had a lower education level, a lower income level, and that they were divorced, widowed, or separated, frequent physical distress was more common.
This pattern was similar for those reporting mental distress; thus, these demographic variables were entered as covariates in the latent class analyses. The latent class models with three latent classes provided the best fit for all four health domains. 


\section{Health risk behaviors}

About one out of every ten (9\%) of COPD respondents belonged to the highest risk class for the five health risk behaviors (Figure 2). Of these, 62.6\% smoked every day, $51.1 \%$ reported binge drinking in the past 30 days, $73.7 \%$ were heavy drinkers, 5.4\% used e-cigarettes daily, and $4.2 \%$ used smokeless tobacco daily. Approximately two out of every ten $(22 \%)$ of the COPD population made up an intermediate class: $55.6 \%$ smoked every day, $49.1 \%$ reported binge drinking, $83.6 \%$ were heavy drinkers, $2.9 \%$ used e-cigarettes daily, and 3.0\% used smokeless tobacco daily. In the remaining $68.9 \%$ of the COPD population (low risk), $22.9 \%$ smoked every day, $11.4 \%$ reported binge drinking, $44.0 \%$ were heavy drinkers, $9.1 \%$ used e-cigarettes daily, and $1.4 \%$ used smokeless tobacco daily.

\section{Comorbidities}

About $32 \%$ of the COPD population reported being in the multiple condition class, which represented the highest risk class for the six health conditions (Figure 3): $92 \%$ in this class reported having asthma, 35.6\% reported diabetes, $24.1 \%$ reported cancer, $22.1 \%$ reported cardiovascular disease (CVD), 91.1\% reported arthritis, and 80.6\% reported depressive symptoms. About $51.5 \%$ of the COPD population reported intermediate conditions for the six health conditions: $85.6 \%$ in this class reported having asthma, $27.2 \%$ reported diabetes, 38.3\% reported cancer, $24.9 \%$ reported CVD, $63.2 \%$ reported arthritis, and $12.1 \%$ reported depressive symptoms. In the remaining $16.4 \%$ of the COPD population with few conditions, $70.6 \%$ in this class reported having asthma, 5.3\% reported diabetes, $4.3 \%$ reported cancer, $0.8 \%$ reported CVD, $16.4 \%$ reported arthritis, and $30.4 \%$ experienced depressive symptoms.

\section{Health care access}

About $6.1 \%$ of the COPD population belonged to the highest risk class in regard to difficulty accessing the three types of health care services (Figure 4 ). Only $43.9 \%$ of patients with limited health care access reported having health care plans, $22.5 \%$ reported having personal health care provider(s), and $14.4 \%$ had routine checkups in the past year. In $54.5 \%$ of the COPD population falling into intermediate access, $99.9 \%$ of these reported having health care plans, 98.3\% having personal health care provider(s), and $91.8 \%$ having coverage in the past year for health checkups. Of the remaining $39.4 \%$ of the COPD population, $93.9 \%$ of these reported having health care plans, 93.0\% having personal health care provider(s), and $83.5 \%$ having coverage in the past year for health checkups.

\section{Preventive vaccinations}

About $20.5 \%$ of COPD population belonged to the highest risk class for the two protective vaccines (Figure 5).

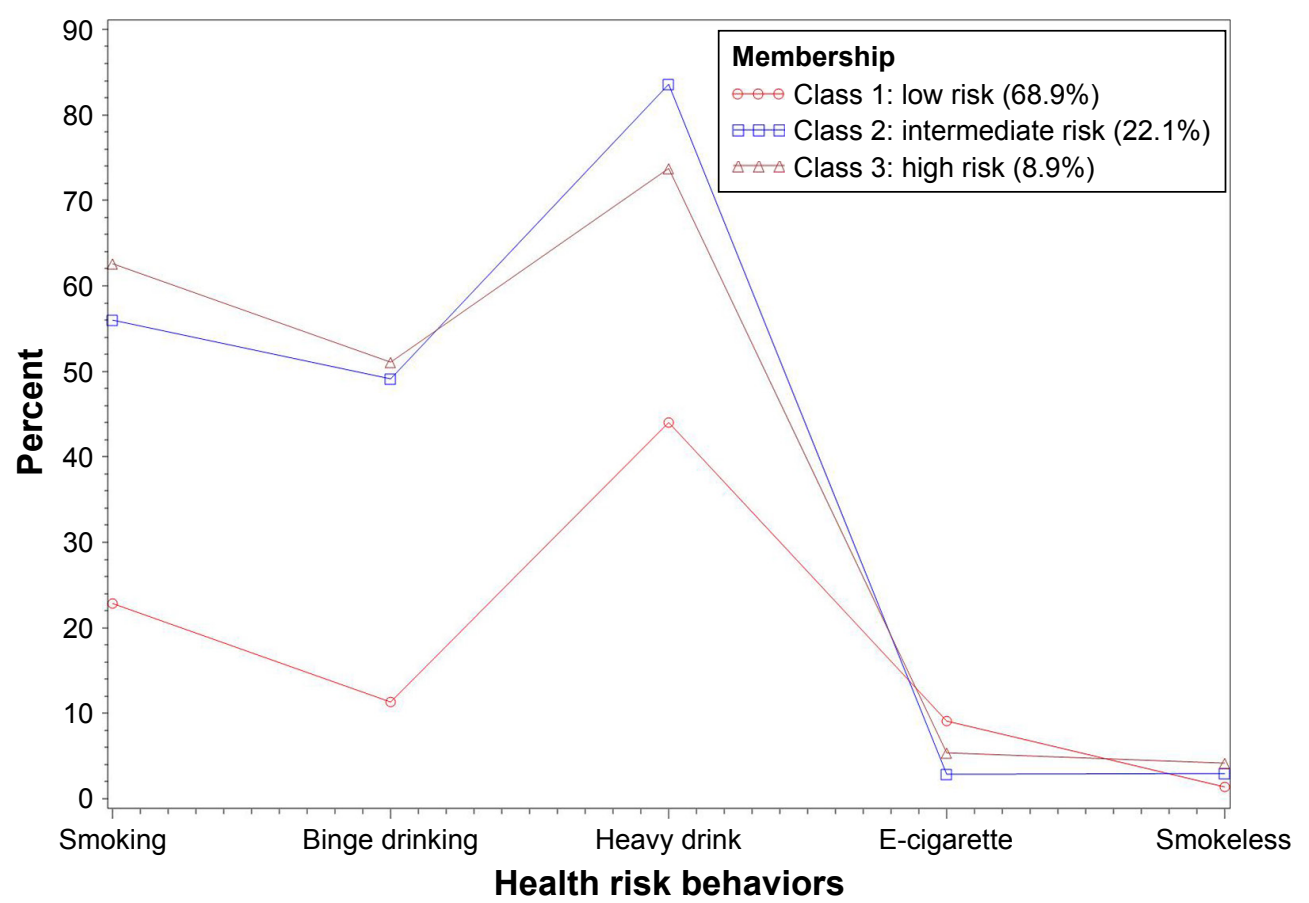

Figure 2 Prevalence probabilities of risky behaviors by latent class, COPD population in 2016 BRFSS data. Behaviors refer to the past 30 days. Binge drinking is defined as $\geq 5$ drinks for men or $\geq 4$ drinks for women on one occasion during the past 30 days. Heavy drinking is defined as $\geq 3$ drinks/day for men or $\geq 2$ drinks/day for women on single occasion during the past 30 days.

Abbreviation: BRFSS, Behavioral Risk Factor Surveillance System. 


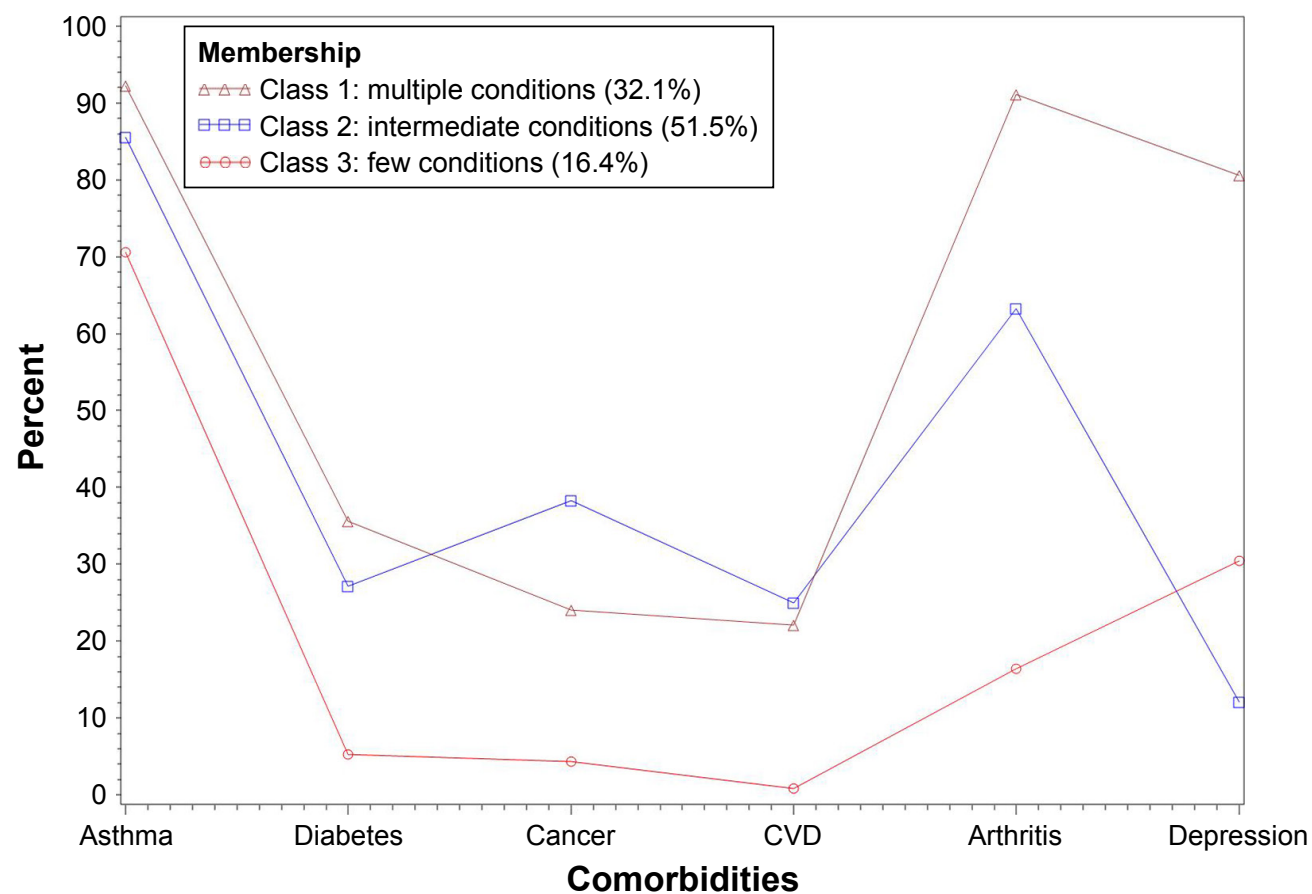

Figure 3 Probabilities of health conditions by latent class, BRFSS, 2016. Health conditions defined as having ever been told by a health professional that they had the condition of asthma, diabetes, cancer, CVD, arthritis, or depressive symptoms.

Abbreviation: BRFSS, Behavioral Risk Factor Surveillance System.

Only $22.1 \%$ had received the pneumonia vaccine and only $25.2 \%$ had received flu shots. About $19.2 \%$ of the COPD population made up an intermediate class: $29.6 \%$ had received pneumonia vaccine and $20.5 \%$ had received flu shots. In the remaining $60.2 \%$ of the COPD population,
99.5\% had received the pneumonia vaccine and $55.3 \%$ reported receiving the flu shot.

Table 2 presents the findings from the logistic regressions assessing the association of each latent class with each of the two outcomes, physical distress and mental distress.

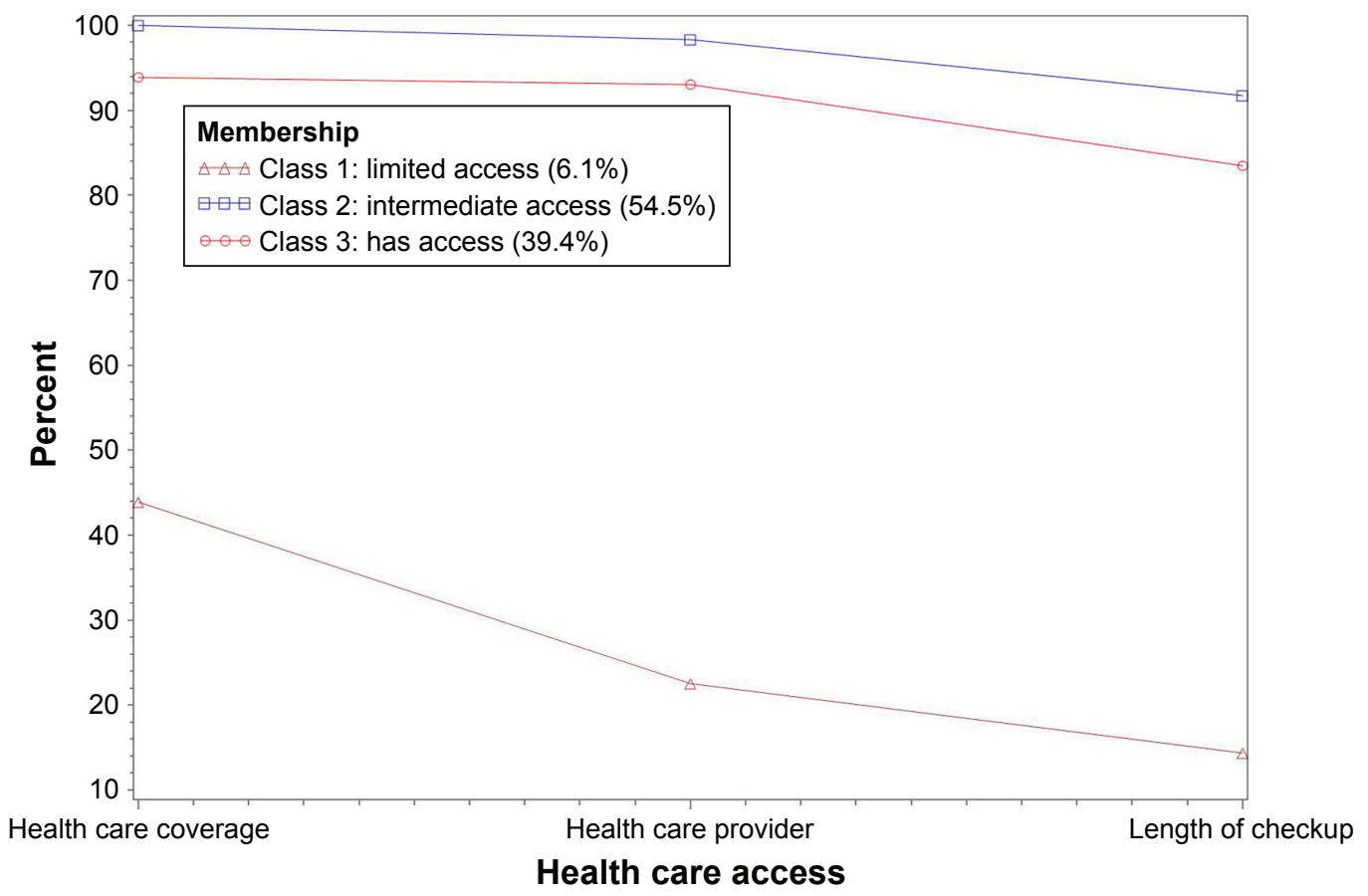

Figure 4 Probabilities of health care access by latent class, COPD population in BRFSS, 2016.

Abbreviation: BRFSS, Behavioral Risk Factor Surveillance System. 


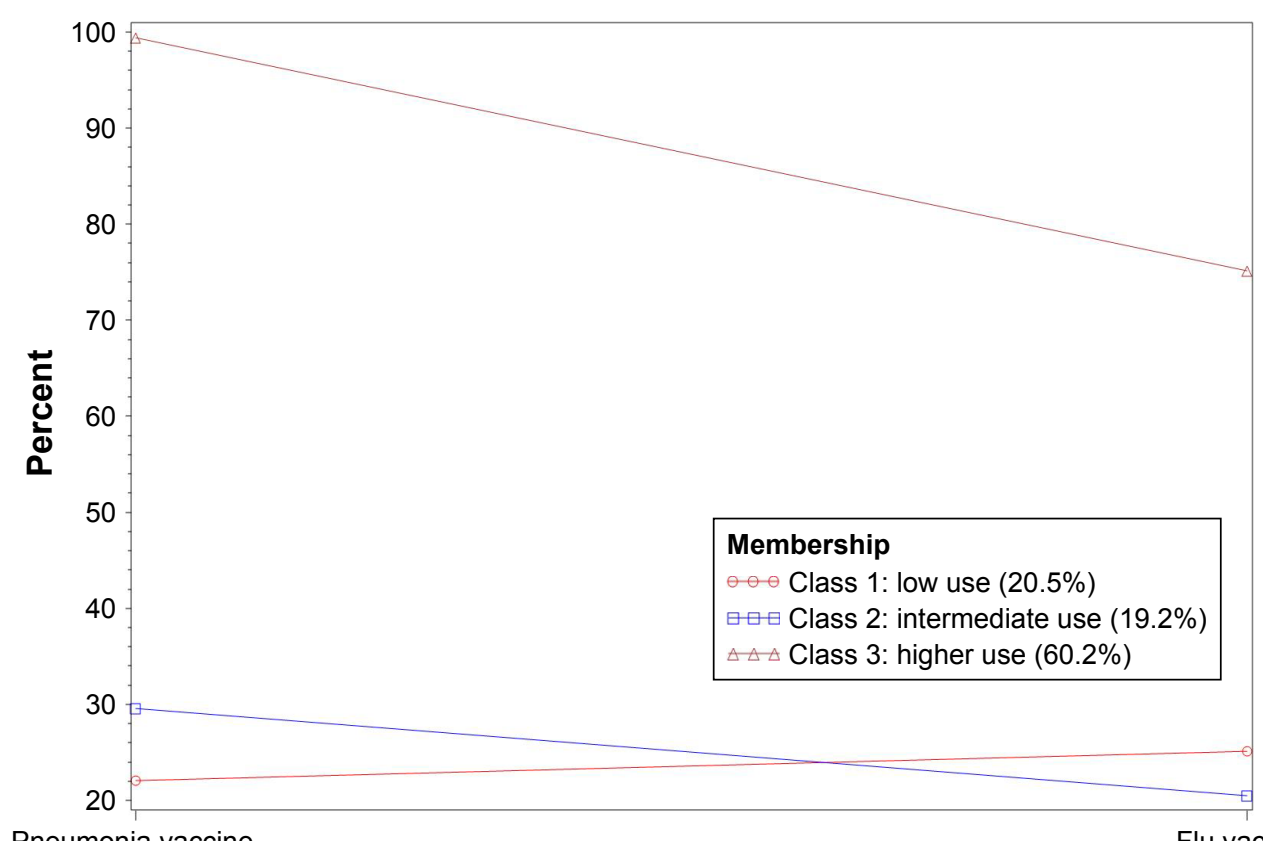

Pneumonia vaccine

\section{Preventive health behaviors}

Figure 5 Prevalence of use of preventive vaccinations by latent class, COPD population in 2016 BRFSS data. Respondents were asked to report if they had ever received the pneumonia vaccine. Respondents were asked to report if they received the flu vaccine during the past year.

Abbreviation: BRFSS, Behavioral Risk Factor Surveillance System.

Respondents with high-risk behaviors, more comorbidities, limited health care access, and low use of preventive vaccinations were more likely to report frequent physical distress as compared to the low-risk respondents. Respondents with high-risk behaviors, more comorbidities, and low use of preventive vaccinations appeared to be more likely to report frequent mental distress than the low-risk group. Two unexpected findings were that those reporting intermediate

Table 2 ORs of frequent physical and mental distress, by health domain, adults reporting diagnosis of COPD, Behavioral Risk Factor Surveillance System, $2016^{\mathrm{a}}$

\begin{tabular}{|c|c|c|c|c|}
\hline \multirow[t]{2}{*}{ Health domain } & \multicolumn{2}{|c|}{ Frequent physical distress } & \multicolumn{2}{|c|}{ Frequent mental distress } \\
\hline & Odds ratio & $95 \% \mathrm{Cl}$ & Odds ratio & $95 \% \mathrm{Cl}$ \\
\hline \multicolumn{5}{|l|}{ Risk behavior } \\
\hline Low risk $(n=5,484)$ & $1.00^{\mathrm{b}}$ & NA & $1.00^{\mathrm{b}}$ & NA \\
\hline Intermediate risk $(\mathrm{n}=9, \mathrm{I} \mid 3)$ & 1.30 & $1.08,1.56^{*}$ & 0.88 & $0.73,1.06$ \\
\hline High risk $(n=18,194)$ & 1.22 & $1.03,1.45^{*}$ & 1.41 & $1.17,1.70 *$ \\
\hline \multicolumn{5}{|l|}{ Comorbidities } \\
\hline Few conditions $(n=5,474)$ & $1.00^{\mathrm{b}}$ & NA & $1.00^{\mathrm{b}}$ & NA \\
\hline Intermediate conditions $(n=|7,24|)$ & 2.03 & $1.69,2.42^{* *}$ & 0.66 & $0.54,0.8 I^{*}$ \\
\hline Multiple conditions $(n=\mid 0,724)$ & 3.49 & $2.90,4.20^{* *}$ & 1.91 & $1.60,2.27^{*}$ \\
\hline \multicolumn{5}{|l|}{ Health care access } \\
\hline Has access $(n=13,186)$ & $1.00^{\mathrm{b}}$ & NA & $1.00^{\mathrm{b}}$ & NA \\
\hline Intermediate access $(n=\mid 8,229)$ & 1.20 & $0.95, I .5 \mathrm{I}$ & 0.46 & $0.36,0.59 *$ \\
\hline Limited access $(n=2,024)$ & 1.63 & $1.29,2.06^{*}$ & 0.91 & $0.72,1.15$ \\
\hline \multicolumn{5}{|l|}{ Preventive vaccines } \\
\hline High use $(n=20,143)$ & $1.00^{\mathrm{b}}$ & NA & $1.00^{\mathrm{b}}$ & NA \\
\hline Intermediate use $(n=6,430)$ & 3.03 & $2.53,3.63^{* *}$ & 2.27 & $1.90,2.72 * *$ \\
\hline Low use $(n=6,863)$ & 2.11 & $1.83,2.44^{* *}$ & 1.18 & I.0I, I.39* \\
\hline
\end{tabular}

Notes: $* P<0.05 ; * *<0.01$. a Analyses were adjusted for age, sex, race/ethnicity, education, marital status, veteran status, annual income, and all other latent variables in Table 2. Frequent physical or mental distress was defined as reporting 14 or more physically or mentally unhealthy days in the last 30 days. ${ }^{b}$ Reference values. Abbreviation: NA, not applicable. 
comorbidities reported less mental distress than the low-risk group ( $\mathrm{OR}=0.66$ ) and those with intermediate health care access were less likely to report mental distress than the low-risk group $(\mathrm{OR}=0.46)$.

\section{Discussion Demographic characteristics of BRFSS respondents with COPD}

Most US adults with COPD included in the 2016 BRFSS were over the age of 45 years, female, white, had a high school education or less, and had an annual income of $<\$ 20,000$. COPD is an increasingly important problem for aging adults ${ }^{30}$ with lower socioeconomic status (SES), ${ }^{31}$ especially females. ${ }^{32,33}$ Differences between genders in pulmonary structure, airway diameter, and diffusion surface contributes to increased COPD diagnoses in women. ${ }^{34}$ Furthermore, women may be especially vulnerable to the negative health effects of tobacco smoke. ${ }^{35}$

Over one-half of adults self-reporting a COPD diagnosis experienced physical and/or mental distress. Factors associated with mental and physical distress included being 45-64 years of age and having lower education and income. Prior research confirms that a disproportionate burden of COPD occurs in people of low SES who often experience worsened COPD health outcomes. ${ }^{14}$ Age, on the other hand, has been shown to be unrelated to several health outcomes (eg, mental health outcomes, HRQoL, or breathlessness) among people with COPD. ${ }^{36}$ These findings indicate the need for innovative solutions that increase availability and access to care, conceivably through telemedicine and telehealth technologies. ${ }^{37}$

\section{Health risk behaviors}

A high proportion of patients with COPD were classified as engaging in high-risk behaviors. This included smoking behaviors and alcohol consumption, either binge drinking or simply drinking above the recommended dietary national guidelines in the last 30 days. ${ }^{38}$ There are several plausible lines of reasoning for this association. First, risk factors associated with distress among our COPD respondents parallel previous research that examined substance use comorbidity. Specifically, being 45-64 years of age, living in lower SES areas, having less education, and experiencing high distress are associated with concurrent risky alcohol and tobacco use. ${ }^{39}$ Second, alcohol and tobacco use have been cited as potentiating the rewarding effects of the other substance. People living with COPD struggle to achieve smoking cessation; ${ }^{40,41}$ therefore, it is possible that alcohol consumption results in cross-reinforcement. ${ }^{42}$ Third, compared to those who do not smoke, smokers are far more likely to develop an alcohol use disorder. ${ }^{43}$ This may be due to alcohol consumption being far more ubiquitous compared to cigarette use in the general population. ${ }^{44,45}$ Future research should explore the effectiveness of programs that simultaneously address smoking cessation and alcohol dependence ${ }^{46}$ in the COPD patient population. It may be that interventions addressing strategies for reducing psychosocial stress through emotional coping mechanisms prove to be most effective in facilitating long-term smoking cessation with fewer relapses. ${ }^{47}$

Although the association between smoking and reduced HRQoL in people with COPD is clear, ${ }^{12}$ little research exists examining how risky alcohol use impacts distress experienced by people living with COPD. Alcohol consumption was once thought to be associated with COPDrelated mortality, but recent empirical evidence questions the link between alcohol use and COPD exacerbations, ${ }^{48}$ especially after adjusting for tobacco use. ${ }^{49}$ The presence of a single anxiety disorder is associated with elevated smoking prevalence. ${ }^{50}$ Future research should explore the temporal relationship between substance use behaviors and physical and mental distress reported by patients with COPD. In particular, future investigations should longitudinally examine if these substances are used to cope with mental and physical distress, or if the use or addiction to these substances is a manifestation of mental and physical distress. Determining best practices for simultaneously reducing alcohol consumption and tobacco smoking behaviors among people living with COPD will be important for future intervention development. This research could have important implications for precisely addressing the biopsychosocial elements of substance use and mental health treatment in the context of COPD self-management.

Less than $10 \%$ of respondents self-reporting a COPD diagnosis used e-cigarettes (also known as vaping) and smokeless tobacco; however, respondents in the low-healthrisk-behavior class showed slightly higher rates of e-cigarette use than respondents in the intermediate- and high-risk classes. Use of e-cigarettes is associated with increased odds of being diagnosed with COPD as well as worse pulmonary outcomes in people living with COPD. ${ }^{51,52}$ E-cigarettes may help facilitate cessation of conventional tobacco cigarette use among smokers with COPD; however, little is known about whether regular e-cigarette use may reduce health risks in COPD that are traditionally associated with smoking tobacco (eg, limit frequency of dyspnea exacerbations). ${ }^{53}$ While results from this study suggest that e-cigarette use is not yet common among US adults living with COPD, future research should examine the extent to which e-cigarette 
use represents a tobacco harm reduction mechanism for ex-smokers diagnosed with COPD.

\section{Comorbid conditions}

Approximately one-third of patients with COPD were in the multiple condition class, which supports the fact that COPD is associated with significantly higher comorbidities compared to other chronic diseases. ${ }^{54}$ Of the six comorbidities considered in this analysis, the largest proportion of multi-morbid patients with COPD reported living with asthma, arthritis, and depression. Among those living with COPD, high prevalence of these comorbidities results in severe consequences such as higher mortality, reduced HRQoL, and higher risk of emergency room and hospital visits. ${ }^{55,56}$

The percentage of patients with COPD who also reported arthritis in this study varied across risk classes (few conditions: $16.4 \%$; intermediate conditions: $63.2 \%$; and multiple condition: $91.1 \%$ ), meaning that arthritis is a more significant concern for patients experiencing multiple illnesses as compared to those experiencing fewer illnesses. In addition, over $70 \%$ of respondents with COPD in each risk class reported being diagnosed with asthma, suggesting that asthma and COPD are still misdiagnosed or mistaken for one another despite their unique physiological manifestations and diagnostic/treatment procedures. ${ }^{57}$

The proportion of patients reporting depression with fewer comorbid conditions was actually greater than that for patients in the intermediate risk category. A majority of respondents in this intermediate risk category reported living with both asthma and arthritis, the effects of which are associated with mental health distress. ${ }^{58,59}$ Slightly more than $80 \%$ of BRFSS respondents with COPD in the highest risk class reported depressive symptoms. As COPD progresses, adults experience noteworthy declines in physical activity ${ }^{60}$ and HRQoL that are exacerbated by poor mental health.,61 Patients with COPD who experience anxiety and depression typically also show higher levels of dyspnea (ie, shortness of breath) compared to non-depressed patients, even though objective respiratory impairment is similar in both depressed and non-depressed patients. ${ }^{61}$ Further, depressed patients with COPD are at an increased risk of experiencing greater all-cause hospitalization leading to mortality. ${ }^{62}$

Effective treatments and interventions for mental health distress can substantially improve HRQoL outcomes for comorbid patients living with COPD. ${ }^{63}$ Future research should examine how distinct combinations of comorbid conditions can impact mental health outcomes among patients living with COPD. Unique interaction effects of specific comorbidities may predict depressive symptoms in COPD more so than sheer number of conditions patients may be living with. In addition, symptoms of physical distress in comorbid patients should be explored further to assist health care providers in developing more tailored treatment plans for this sub-group of patients with COPD.

\section{Access to health care}

Few studies have investigated associations between accessto-care factors and quality of life among people with COPD. In this study, the overwhelming majority of respondents reported having at least intermediate access to health care; however, less than half $(43.9 \%)$ in the highest risk class reported having a health care plan; only $22.5 \%$ reported having a primary care provider; and even fewer (14.4\%) underwent a physical/checkup in the past year. Access to care represents a restrictive barrier to effective disease management for high-risk patients with COPD. Greater availability of (and accessibility to) pulmonary care specialists may be key in reducing emergency room and hospital utilization among high-risk patients with COPD. ${ }^{64}$ Future research should explore multi-level barriers to specialized and routine care for patients with COPD. For example, to slow down the progression of COPD, annual physicals are extremely important for monitoring changes in lung functioning and should be encouraged by health care providers. ${ }^{62}$

\section{Preventive vaccinations}

A large chasm was present between higher risk latent classes and the low-risk classes with regard to vaccination rates. Only about one-quarter of respondents with COPD in the highest risk (low use) class reported getting their annual flu shot, while slightly more than $20 \%$ reported being vaccinated against pneumonia. Low vaccination rates are particularly concerning for people living with COPD because they are vulnerable to influenza, which can cause both breathing exacerbations and pneumonia, often resulting in significant health care burdens and even premature death. ${ }^{65}$

Among the $60 \%$ of people with COPD in the low risk (high use) class for preventive vaccinations, almost all reported receiving the pneumonia vaccination (99.5\%), yet only about half (55.3\%) obtained their annual flu vaccination. Prior analyses of 2012 BRFSS data showed that close to $50 \%$ of patients with COPD were not vaccinated against influenza, ${ }^{11,66}$ which is similar to the flu vaccine rate reported here. The target HP 2020 recommendation for flu vaccination is $90 \%$ for adults living with chronic conditions. ${ }^{67}$ Despite widespread efforts to promote the annual flu vaccine and 
extremely positive benefit-to-risk ratios for seasonal influenza vaccination in patients with $\mathrm{COPD},{ }^{65,68}$ the proportion of people living with COPD who receive their flu vaccine is not sufficient. To improve these rates, physicians and pulmonologists should strongly advocate for vaccinations when administering standard respiratory assessments to patients. This practice may increase influenza vaccination rates in adults with COPD. ${ }^{69}$ People living with COPD who are susceptible to influenza must receive clear and convincing messages about the overwhelming benefits of receiving their vaccinations on a regular schedule. Future research should seek to understand attitudes and beliefs toward preventive vaccines among people living with COPD. Many patients with COPD feel helpless ${ }^{70}$ and may be skeptical of protective benefits afforded by vaccination. In addition to understanding more about these intrapersonal modifying factors, research is also needed to examine how other upstream ecological factors (ie, cost, access to care) may inhibit receipt of vaccines, particularly among low-income adults living with COPD.

\section{Influence of risk class on physical and mental distress}

As expected, respondents with higher risk behaviors, more comorbidities, limited health care access, and low use of preventive vaccines were more likely to report frequent physical distress. Respondents demonstrating higher risk behaviors, multiple comorbidities, and low use of preventive services were more likely to report frequent mental distress. Having access to health insurance and health care may have less bearing on the extent to which mental health problems (eg, depression and anxiety) are experienced by people with COPD. Pulmonary rehabilitation has also been identified as an effective course of treatment for treating anxiety and depression in patients with COPD ${ }^{71}$ yet few patients are able to access these specialized, often fee-for-service, programs. Future studies should examine whether lack of specialized mental health counseling and/or treatments, such as those available in most pulmonary rehabilitation programs, lead to increased mental distress among people living with COPD.

\section{Limitations}

The BRFSS provides a robust nationally representative set of responses, yet the analysis of BRFSS data is associated with several limitations. ${ }^{72}$ First, the cross-sectional nature of BRFSS data precludes interpretations about the temporal sequence of associations between risk factors and poor HRQoL. In other words, it is difficult to determine whether risky health behaviors, comorbidities, and lack of vaccinations/health care are causes for physical and mental distress, or whether distress itself actually contributed to these risk factors. Further studies are needed to prospectively evaluate trends between comorbidities, access to health care, and higher rates of mental health distress among people living with COPD.

Second, BRFSS data are based on unvalidated self-reports via telephone survey. Data may be affected by recall bias. For example, the item used to identify respondents with COPD could not be validated against recommended diagnostic tests such as spirometry. ${ }^{73}$ Nevertheless, several other studies examining BRFSS data used similar inclusion criteria for identifying respondents diagnosed with COPD. ${ }^{74-76}$ Limited knowledge about COPD and uncertainty about diagnostic status can lead to misreporting a clinical diagnosis. For example, COPD is often misreported and misdiagnosed as asthma, ${ }^{57}$ especially among women. ${ }^{77}$ Because of this, the individual, social, and biomedical characteristics of respondents in this study may not have been wholly representative of the general US COPD population. Future studies of patients with COPD should seek to collect spirometry data from patients to confirm their COPD diagnosis prior to analyzing personal risk factors that may be associated with physical and mental distress. Such population-based research would directly address several of the major goals outlined in the US National COPD Action Plan. ${ }^{7}$

Although BRFSS is a telephone-based survey and excludes individuals with low SES who do not have telephones, one strength of this study is that it is based on a very large sample of respondents randomly drawn from the general population rather than from clinically selected groups of patients with COPD. Because of this, the generalizability of our results represents a positive characteristic of this secondary data analysis.

Limitations of the LCM approach used to analyze BRFSS data include relatively limited theoretical and empirical support for the four domains considered in this study. For example, classes of smaller size identified in this study may simply represent outliers in the BRFSS data. Nevertheless, this study attempted to model analyses conducted by Jiang and Zack, ${ }^{15}$ who advocated for applying LCM to complex datasets targeting people with specific health conditions (eg, COPD).

\section{Conclusion}

This secondary data analysis of updated 2016 BRFSS data identified high-risk Americans with COPD who could benefit from disease management and secondary/tertiary 
health promotion interventions that may improve HRQoL. Specifically, this analysis identifies patient subgroups with high probabilities of risky behaviors who are living with multiple comorbidities. Future public health research should address noted disparities in risk factors among this vulnerable, often overlooked, patient population. Future epidemiological and intervention research is needed to address factors associated with mental and physical distress in adults living with a COPD diagnosis.

\section{Acknowledgment}

The authors wish to acknowledge Arjun Mohan, MD, for his important contributions in critically revising the article for important intellectual content and providing final approval of the version to be published.

\section{Author contributions}

All authors contributed to data analysis, drafting or revising the article, gave final approval of the version to be published, and agree to be accountable for all aspects of the work.

\section{Disclosure}

The authors report no conflicts of interest in this work.

\section{References}

1. Greenlund KJ, Liu Y, Deokar AJ, Wheaton AG, Croft JB. Association of chronic obstructive pulmonary disease with increased confusion or memory loss and functional limitations among adults in 21 states, 2011 behavioral risk factor surveillance system. Prev Chronic Dis. 2016;13: E02. doi: $10.5888 / \mathrm{pcd} 13.160231$

2. Wheaton AG, Cunningham TJ, Ford ES, Croft JB. Employment and activity limitations among adults with chronic obstructive pulmonary diseaseUnited States, 2013. MMWR Morb Mortal Wkly. 2015;64(11):289-295.

3. Tselebis A, Pachi A, Ilias I, et al. Strategies to improve anxiety and depression in patients with COPD: a mental health perspective. Neuropsychiatr Dis Treat. 2016;12:297-328. doi:10.2147/NDT.S79354

4. Maurer J, Rebbapragada V, Borson S, et al. Anxiety and depression in COPD. Chest. 2008;134:43-56. doi:10.1378/chest.08-0342

5. Ford ES, Murphy LB, Khavjou O, Giles WH, Holt JB, Croft JB. Total and state-specific medical and absenteeism costs of COPD among adults aged $\geq 18$ years in the United States for 2010 and projections through 2020. Chest. 2015;147(1):31-45. doi:10.1378/chest.14-0972

6. Office of Disease Prevention and Health Promotion. Respiratory diseases, healthy people 2020. Available from: https://www.healthypeople. gov/2020/topics-objectives/topic/respiratory-diseases. Accessed September 18, 2018.

7. National Heart Lung and Blood Institute. COPD national action plan. Available from: https://www.nhlbi.nih.gov/sites/default/files/media/ docs/COPD\%20National\%20Action\%20Plan\%20508_0.pdf. Accessed September 18, 2018.

8. Godtfredsen NS, Lam TH, Hansel TT, et al. COPD-related morbidity and mortality after smoking cessation: status of the evidence. Eur Respir J. 2008;32(4):844-853. doi:10.1183/09031936.00160007

9. Schauer GL, Wheaton AG, Malarcher AM, Croft JB. Smoking prevalence and cessation characteristics among U.S. adults with and without COPD: findings from the 2011 behavioral risk factor surveillance system. Chronic Obstr Pulm Dis. 2014;11(6):697-704. doi:10. 3109/15412555.2014.898049
10. Centers for Disease Control and Prevention. Adults with chronic conditions: get vaccinated. Available from: https://www.cdc.gov/features/ vaccineschronicconditions/index.html. Accessed October 15, 2018.

11. Hsu DJ, North CM, Brode SK, Celli BR. Identification of barriers to influenza vaccination in patients with chronic obstructive pulmonary disease: analysis of the 2012 Behavioral Risk Factors Surveillance System. Chronic Obstr Pulm Dis. 2016;3(3):620-627. doi:10.15326/ jcopdf.3.3.2015.0156

12. Cheruvu VK, Odhiambo LA, Mowls DS, Zullo MD, Gudina AT. Health-related quality of life in current smokers with COPD: factors associated with current smoking and new insights into sex differences. Int J Chron Obstruct. 2016;11:2211-2219. doi:10.2147/COPD.S106207

13. Mallia P, Johnston SL. Influenza infection and COPD. Int J Chron Obstruct. 2007;2(1):55-64.

14. Pleasants RA, Riley IL, Mannino DM. Defining and targeting health disparities in chronic obstructive pulmonary disease. Int J Chron Obstruct. 2016;11:2475-2496. doi:10.2147/COPD.S79077

15. Jiang Y, Zack MM. A latent class modeling approach to evaluate behavioral risk factors and health-related quality of life. Prev Chronic Dis. 2011;8(6):A137.

16. Centers for Disease Control and Prevention. Behavior risk factor surveillance system. Overview: BRFSS 2016. Available from: https://www. cdc.gov/brfss/annual_data/2016/pdf/overview_2016.pdf. Accessed September 18, 2018.

17. Moreno D, Barroso J, Garcia A. Vaccines for patients with COPD. Recent Pat Inflamm Allergy Drug Discov. 2015;9(1):23-30.

18. Lisspers K, Johansson G, Jansson C, et al. Improvement in COPD management by access to asthma/COPD clinics in primary care: data from the observational PATHOS study. Respir Med. 2014;108(9):1345-1354. doi:10.1016/j.rmed.2014.06.002

19. Wijngoven H, Kriegsman D, Hesselink A, Haan M, Schellevis F. The influence of co-morbidity on health-related quality of life in asthma and COPD patients. Respir Med. 2003;97:468-475.

20. Centers for Disease Control and Prevention. Measuring Healthy Days. Atlanta (GA): CDC. Available from: https://www.cdc.gov/hrqol/pdfs/ mhd.pdf. Accessed October 15, 2018.

21. Reynolds C, Kamphaus R. Major depressive disorder. Pearson Clin. 2013. Available from: Accessed April 5, 2019.

22. National Institute of Mental Health. Depression. Available from: https:// www.ncbi.nlm.nih.gov/pubmed/. Accessed October 15, 2018.

23. Li C, Ford ES, Mokdad AH, Balluz LS, Brown DW, Giles WH. Clustering of cardiovascular disease risk factors and health-related quality of life among US adults. Value Health. 2008;11(4):689-699. doi:10.1111/j.1524-4733.2007.00307.x

24. Okoro CA, Brewer RD, Naimi TS, Moriarty DG, Giles WH, Mokdad AH. Binge drinking and health-related quality of life: do popular perceptions match reality? Am J Prev Med. 2004;26(3):230-233. doi:10.1016/j.amepre.2003.10.022

25. Flaherty BP. Assessing reliability of categorical substance use measures with latent class analysis. Drug Alcohol Depend. 2002;68(Suppl 1): S7-S20. doi:10.1016/S0376-8716(02)00210-7

26. Strauss SM, Rindskopf DM, Astone-Twerell JM, Des Jarlais DC, Hagan H. Using latent class analysis to identify patterns of hepatitis C service provision in drug-free treatment programs in the. Drug Alcohol Depend. 2006;83(1):15-24. doi:10.1016/j.drugalcdep.2005.10.005

27. Monga N, Rehm J, Fischer B, et al. Using latent class analysis (LCA) to analyze patterns of drug use in a population of illegal opioid users. Drug Alcohol Depend. 2007;88(1):1-8. doi:10.1016/j.drugalcdep. 2006.08.029

28. Guo J, Wall M, Amemiya Y. Latent class regression on latent factors. Biostatistics. 2006;7(1):145-163. doi:10.1093/biostatistics/kxi046

29. SAS. Version 9.4. Cary (NC): SAS Institute Inc: 2017.

30. Jarad N. Chronic obstructive pulmonary disease (COPD) and old age? Chron Respir Dis. 2011;8(2):143-151. doi:10.1177/1479972311407218

31. Eisner MD, Blanc PD, Omachi TA, et al. Socioeconomic status, race and COPD health outcomes. J Epidemiol Community Health. 2011;65(1): 26-34. doi:10.1136/jech.2009.089722 
32. Aryal S, Diaz-Guzman E, Mannino DM. COPD and gender differences: an update. Transl Res. 2013;162(4):208-218. doi:10.1016/j.trsl. 2013.04.003

33. Han MK, Postma D, Mannino DM, et al. Gender and chronic obstructive pulmonary disease: why it matters. Am J Respir Crit Care Med. 2007; 176(12):1179-1184. doi:10.1164/rccm.200704-553CC

34. Harms C. Does gender affect pulmonary function and exercise capacity? Respir Physiol Neurobiol. 2006;151(2-3):124-131. doi:10.1016/j.resp. 2005.10.010

35. Kirkpatrick D, Dransfield MT. Racial and sex differences in chronic obstructive pulmonary disease susceptibility, diagnosis, and treatment. Curr Opin Pulm Med. 2009;15(2):100-104. doi:10.1097/MCP 0b013e3283232825

36. Holm KE, Plaufcan MR, Ford DW, et al. The impact of age on outcomes in chronic obstructive pulmonary disease differs by relationship status. J Behav Med. 2014;37(4):654-663. doi:10.1007/ s10865-013-9516-7

37. Kvedar J, Coye MJ, Everett W. Connected health: a review of technologies and strategies to improve patient care with telemedicine and telehealth. Health Aff. 2014;33(2):194-199. doi:10.1377/hlthaff.2013.0992

38. Office of disease prevention and health promotion. Alcohol -2015-2020 Dietary Guidelines. Available from: https://health.gov/dietaryguidelines/2015/guidelines/appendix-9/. Accessed October 15, 2018.

39. Bonevski B, Regan T, Paul C, Baker AL, Bisquera A. Associations between alcohol, smoking, socioeconomic status and comorbidities: evidence from the 45 and Up Study. Drug Alcohol Rev. 2014;33(2) 169-176. doi:10.1111/dar.12104

40. Eklund BM, Nilsson S, Hedman L, Lindberg I. Why do smokers diagnosed with COPD not quit smoking? - A qualitative study. Tob Induc Dis 2012;10(1):17. doi:10.1186/1617-9625-10-17

41. Aumann I, Tedja L, von der Schulenburg JM. Experiences of COPD patients with existing smoking cessation programs and their preferences for improvement - a qualitative analysis. Tob Induc Dis. 2016;14(1):31 doi:10.1186/s12971-016-0097-4

42. Adams S. Psychopharmacology of tobacco and alcohol comorbidity: a review of current evidence. Curr Addict Rep. 2017;4(1):25-34. doi:10. 1007/s40429-017-0129-z

43. Grucza RA, Bierut LJ. Cigarette smoking and the risk for alcohol use disorders among adolescent drinkers. Alcohol Clin Exp Res. 2006 30(12):2046-2054. doi:10.1111/j.1530-0277.2006.00255.x

44. National Institute on Alcohol Abuse and Alcoholism (NIAAA). Alcohol facts and statistics. Available from: https://www.ncbi.nlm.nih.gov/ pubmed/. Accessed September 18, 2018.

45. Centers for Disease Control and Prevention. Smoking and tobacco use; fact sheet; adult cigarette smoking in the United States. Available from: https://www.cdc.gov/tobacco/data_statistics/fact_sheets/adult_data/ cig_smoking/index.htm. Accessed October 15, 2018.

46. Friend K, Pagano M. Smoking cessation and alcohol consumption in individuals in treatment for alcohol use disorders. J Addict Dis. 2005; 24(2):61-75. doi:10.1300/J069v24n02_06

47. Slopen N, Kontos E, Ryff C, Ayanian J, Albert M, Williams D. Psychosocial stress and cigarette smoking persistence, cessation, and relapse over 9-10 years: a prospective study of middle-aged adults in the United States. Cancer Causes Control. 2013;24(10):1849-1863. doi:10.1007/ s10552-013-0262-5

48. Wetherbee EE, Niewoehner DE, Sisson JH, Lindberg SM, Connett JE, Kunisaki KM. Self-reported alcohol intake and risk of acute exacerbations of chronic obstructive pulmonary disease: a prospective cohort study. Int J Chron Obstruct. 2015;10:1363-1370. doi:10.2147/COPD S 86572

49. Greene CC, Bradley KA, Bryson CL, et al. The association between alcohol consumption and risk of COPD exacerbation in a veteran population. Chest. 2008;134(4):761-767. doi:10.1378/chest.07-3081

50. Cougle JR, Zvolensky MJ, Fitch KE, Sachs-Ericsson N. The role of comorbidity in explaining the associations between anxiety disorders and smoking. Nicotine Tob Res. 2010;12(4):355-364. doi:10.1093/ntr/ ntq006
51. Perez M, Atuegwu N, Mead E, Oncken C, Mortensen E. E-Cigarette use is associated with emphysema, chronic bronchitis and COPD. Am J Respir Crit Care Med. 2018;197:A6245.

52. Bowler RP, Hansel NN, Jacobson S, et al. Electronic cigarette use in US adults at risk for or with COPD: analysis from two observational cohorts. J Gen Intern Med. 2017;32(12):1315-1322. doi:10.1007/ s11606-017-4150-7

53. Morjaria JB, Mondati E, Polosa R. E-cigarettes in patients with COPD: current perspectives. Int J Chron Obstruct. 2017;12:3203-3210. doi:10. 2147/COPD.S135323

54. Yin HL, Yin SQ, Lin QY, Xu Y, Xu HW, Liu T. Prevalence of comorbidities in chronic obstructive pulmonary disease patients: a meta-analysis. Medicine (Baltimore). 2017;96(19):e6836. doi:10.1097/ MD.0000000000006836

55. Martinez CH, Mannino DM, Divo MJ. Defining COPD-related comorbidities, 2004-2014. Chronic Obstr Pulm Dis. 2014;1(1):51-63. doi:10. 15326/jcopdf.1.1.2014.0119

56. Kumbhare SD, Beiko T, Wilcox SR, Strange C. Characteristics of COPD patients using United States emergency care or hospitalization. Chronic Obstr Pulm Dis. 2016;3(2):539-548. doi:10.15326/ jcopdf.3.2.2015.0155

57. Tinkelman DG, Price DB, Nordyke RJ, Halbert RJ. Misdiagnosis of COPD and asthma in primary care patients 40 years of age and over. J Asthma. 2006;43(1):75-80. doi:10.1080/02770900500448738

58. Alahmari AD, Kowlessar BS, Patel AR, et al. Physical activity and exercise capacity in patients with moderate COPD exacerbations. Eur Respir J. 2016;48(2):340-349. doi:10.1183/13993003.01105-2015

59. Di Marco F, Terraneo S, Roggi MA, et al. Physical activity impairment in depressed COPD subjects. Respir Care. 2014;59(5):726-734. doi:10. 4187/respcare. 02848

60. Hayatbakhsh MR, Najman JM, Clavarino A, Bor W, Williams GM, O'Callaghan MJ. Association of psychiatric disorders, asthma and lung function in early adulthood. J Asthma. 2010;47(7):786-791. doi:10. 3109/02770903.2010.489141

61. He Y, Zhang M, Lin EH, et al. Mental disorders among persons with arthritis: results from the World Mental Health Surveys. Psychol Med. 2008;38(11):1639-1650. doi:10.1017/S0033291707002474

62. Welte T, Vogelmeier C, Papi A. COPD: early diagnosis and treatment to slow progression. Int J Clin Pract. 2014;69(3):336-349. doi:10.1111/ ijcp. 12522

63. Alam A, Huijon R, Alla V, Rivera N. COPD comorbid with mental illness: what psychiatrists can do: you can do a great deal to ease patients' pulmonary distress as you manage their psychiatric illness. Curr Psychiatry. 2016;15(5):68-74.

64. Kim M, Ren J, Tillis W, Asche CV, Kim IK, Kirkness CS. Explaining the link between access-to-care factors and health care resource utilization among individuals with COPD. Int J Chron Obstruct. 2016; 11:357-367. doi:10.2147/COPD.S95717

65. Sanei F, Wilkinson T. Influenza vaccination for patients with chronic obstructive pulmonary disease: understanding immunogenicity, efficacy and effectiveness. Ther Adv Respir Dis. 2016;10(4):349-367. doi:10. $1177 / 1753465816646050$

66. Arabyat RM, Raisch DW, Bakhireva L. Influenza vaccination for patients with chronic obstructive pulmonary disease: implications for pharmacists. Res Social Adm Pharm. 2018;14(2):162-169. doi:10. 1016/j.sapharm.2017.02.010

67. Office of Disease Prevention and Health Promotion. Immunization and infectious diseases: healthy people 2020. Available from: https://www healthypeople.gov/2020/topics-objectives/topic/immunization-andinfectious-diseases/national-snapshot. Accessed September 20, 2018.

68. Bekkat-Berkani R, Wilkinson T, Buchy P, et al. Seasonal influenza vaccination in patients with COPD: a systematic literature review. BMC Pulm Med. 2017;17(1):79. doi:10.1186/s12890-017-0500-9

69. Mowls DS, Cheruvu VK, Zullo MD. Influenza vaccination in adults with chronic obstructive pulmonary disease: the impact of a diagnostic breathing test on vaccination rates. PLoS One. 2013;8(6):e67600. doi:10.1371/journal.pone.0067600 
70. Omachi TA, Katz PP, Yelin EH, et al. The COPD Helplessness Index: a new tool to measure factors affecting patient self-management. Chest. 2010;137(4):823-830. doi:10.1378/chest.09-0764

71. Cafarella P, Effing T, Usmani Z, Frith P. Treatments for anxiety and depression in patients with chronic obstructive pulmonary disease: a literature review. Respirology. 2012;17(4):627-638. doi:10.1111/ j.1440-1843.2012.02148.x

72. Powell-Griner E. Centers for Disease Control and Prevention. Uses and limitations of the behavioral risk factor surveillance system data. Available from: https://www.amstat.org/sections/srms/Proceedings/ papers/1998_033.pdf. Accessed September 18, 2018.

73. Vogelmeier CF, Criner GJ, Martinez FJ, et al. Global strategy for the diagnosis, management, and prevention of chronic obstructive lung disease 2017 reports. GOLD executive summary. Am J Respir Crit Care Med. 2017;195(5):557-582. doi:10.1164/rccm.201701-0218PP
74. Jackson BE, Suzuki S, Coultas D, Singh KP, Bae S. Chronic obstructive pulmonary disease and health-related quality of life in the 2009 Texas behavioral risk factor survey. Health Educ Behav. 2013;40(4):469-479. doi:10.1177/1090198112460053

75. Centers for Disease Control and Prevention. Chronic obstructive pulmonary disease and associated health-care resource use - North Carolina, 2007 and 2009. MMWR Morb Mortal Wkly Rep. 2012;61(8):143-146.

76. Cunningham T, Ford E, Croft J, Merrick M, Rolle I, Giles W. Sex-specific relationships between adverse childhood experiences and chronic obstructive pulmonary disease in five states. Int J Chron Obstruct Pulmon Dis. 2014;9(1):1033-1043. doi:10.2147/COPD.S68226

77. American Lung Association. Taking her breath away: the rise of COPD in women. Available from: https://www.lung.org/our-initiatives/ research/lung-health-disparities/the-rise-of-copd-in-women.html. Accessed January 25, 2019.

\section{Publish your work in this journal}

The International Journal of COPD is an international, peer-reviewed journal of therapeutics and pharmacology focusing on concise rapid reporting of clinical studies and reviews in COPD. Special focus is given to the pathophysiological processes underlying the disease, intervention programs, patient focused education, and self management protocols.

\section{Dovepress}

This journal is indexed on PubMed Central, MedLine and CAS. The manuscript management system is completely online and includes a very quick and fair peer-review system, which is all easy to use. Visit $\mathrm{http}: / /$ www.dovepress.com/testimonials.php to read real quotes from published authors.

Submit your manuscript here: http://www.dovepress.com/international-journal-of-chronic-obstructive-pulmonary-disease-journal 